J Nutr Educ Behav. 2012 ; 44(2): 166-171. doi:10.1016/j.jneb.2011.06.009.

\title{
Family ties to health program: a randomized intervention to improve vegetable intake in children
}

\author{
Rachel G Tabak, PhD ${ }^{1,2}$, Deborah F. Tate, $\mathrm{PhD}^{2}$, June Stevens, PhD, RD ${ }^{2}$, Anna Maria \\ Siega-Riz, $\mathbf{P h D}^{2}$, and Dianne S Ward, EdD ${ }^{2}$ \\ Rachel G Tabak: rtabak@gwbmail.wustl.edu; Deborah F. Tate: dftate@email.unc.edu; June Stevens: \\ June_Stevens@unc.edu; Anna Maria Siega-Riz: siegariz@email.unc.edu; Dianne S Ward: dsward@email.unc.edu \\ ${ }^{1}$ George Warren Brown School of Social Work, Prevention Research Center in St. Louis, \\ Washington University in St. Louis, 660 S. Euclid, Campus Box 8109, St. Louis, MO 63110, USA, \\ phone: 314-362-9653, fax: 314-362-9665 \\ 2Department of Nutrition, Gillings School of Global Public Health, University of North Carolina, \\ CB\# 7461 North Carolina, 27599, USA
}

\begin{abstract}
Objective-Evaluate a home-based intervention targeted toward parents to improve vegetable intake in preschool-aged children.

Methods-4-month, feasibility study of home-based intervention consisting of 4 tailored newsletters, 2 motivational phone calls compared to control: 4 children's books; measured pre-and post parent-reported physical and social home environment and child vegetable intake in 22 intervention and 21 control homes with a child 2-5 years assessed with linear regression of group predicting home environment and diet characteristics post-intervention, adjusting for baseline ( $\mathrm{p}<$. 05 significant).
\end{abstract}

Results-Intervention increased availability of vegetables ( $+1.5 \pm 2.5$ vegetable types vs. $-0.3 \pm$ 2.7, $\mathrm{P}=0.02)$, offering fruits and vegetables for snacks $(+0.95 \pm 1.5$ days/week vs. $-0.05 \pm 1.9$, $\mathrm{P}=0.04)$, self-efficacy $(+2.4 \pm 4.1$ vs. $-0.3 \pm 2.0, \mathrm{P}=0.02)$.

Conclusions and Implications-Suggests potential for home-based interventions to alter parent behaviors such as feeding practices and the home physical environment, which may be steps toward increasing vegetable intake in children.

\section{Keywords}

Vegetable consumption; Parent feeding practices; Preschool-aged children

\footnotetext{
(C) 2011 Society for Nutrition Education. Published by Elsevier Inc. All rights reserved.

Correspondence to: Rachel G Tabak, rtabak@gwbmail . wust l . edu.

Institution at which the work was conducted (differs from the present affiliation of the first author): Department of Nutrition, Gillings School of Global Public Health, University of North Carolina, CB\# 7461 North Carolina, 27599, USA

Publisher's Disclaimer: This is a PDF file of an unedited manuscript that has been accepted for publication. As a service to our customers we are providing this early version of the manuscript. The manuscript will undergo copyediting, typesetting, and review of the resulting proof before it is published in its final citable form. Please note that during the production process errors may be discovered which could affect the content, and all legal disclaimers that apply to the journal pertain.
} 


\section{INTRODUCTION}

Adequate vegetable intake, as part of an overall healthy life style has the potential to prevent obesity and chronic disease ${ }^{1,2}$. Eating vegetables during early childhood is especially important because health behaviors continue into adolescence and young adulthood ${ }^{3}$. Children develop disease risk factors early ${ }^{4}$, and childhood exposures may influence lifelong disease risks ${ }^{5,6}$. Data from the 1999-2000 National Health and Nutrition Examination Survey show that neither children 2-3 years old nor 4-8 years old consume the recommended amounts of fruits or vegetables ${ }^{7}$.

Since parents determine many aspects of the home environment, their decisions shape health habits of young children ${ }^{8}$. Within the home, both physical features (availability and accessibility) and social factors (feeding practices, parental modeling and policies within the home) can influence eating behavior ${ }^{9}$. Modifications to the home environment is a potential approach to increase vegetable intake in children ${ }^{10}$. Experimental ${ }^{11}$ and observational studies ${ }^{12,13}$ have shown that preferences can be changed from sweet foods to vegetables, by changing parent feeding practices.

Interventions targeted at parents of preschoolers, focusing on the parent as an agent of dietary change, may be effective for influencing child dietary behavior; this has been effective in weight management programs for obese children ${ }^{14,15}$. However, such approaches are often resource-intensive, making implementation and/or dissemination difficult. Bauman and colleagues showed the efficacy of brief, family-based interventions for alcohol and drug abuse prevention including newsletters and periodic phone calls ${ }^{16-19}$; this approach might be feasible for improving dietary habits.

The Family Ties to Health program was designed to improve vegetable intake in young children, using a 4-month, home-based intervention targeting the parent and home environment. In this paper we describe the program and an evaluation of the program's effectiveness, including its impact on vegetable consumption, parent self-efficacy, and home environment factors as well as parents' receptivity to this approach.

\section{METHODS}

\section{Participants and Recruitment}

A convenience sample of 50 parent-child dyads, with at least one child age 2 to 5 years, was recruited through childcare centers, listservs, and community postings. Interested parents responded to recruitment materials and were screened by phone. Additional eligibility criteria included having lived in their current residence and planning to stay in that residence for at least 6 months. If the family had more than one eligible child, the eldest was selected as the reference child; parents were instructed to think specifically about this child while completing questionnaires. Two control group families had incomplete baseline assessments; three intervention and two control families did not complete follow-up assessments. This final sample included 22 intervention and 21 control families. 


\section{Procedures}

Parents who enrolled agreed to a home visit or brought their child to a central study location for height and weight measurement. At this meeting, parents received three baseline surveys: the Healthy Home Checklist, the Parenting Survey, and a Food Frequency Questionnaire (FFQ). Parents completed these measures independently and did not receive assistance by project staff. After this meeting, families were randomly assigned to the intervention or the control group. Post-intervention surveys were mailed to all participants, and intervention families were sent an additional Program Evaluation questionnaire for return in prepaid envelopes. Implemented between April and December 2009, participation lasted approximately 5 months from baseline to follow-up data collection. Participants received $\$ 25$ for each set of surveys returned ( $\$ 50$ total).Informed consent was obtained from the parent, and all study procedures were reviewed and approved by the UNC Public Health-Nursing Institutional Review Board.

\section{Intervention}

The intervention included two phone calls and four newsletters over four months. After returning baseline surveys, intervention group parents received the first individual phone call. A registered dietitian trained in the use of motivational interviewing techniques conducted calls at a time convenient for the parent. The first call addressed vegetable and food issues based on the baseline surveys, and the dietitian helped parents select one primary target area for improvement during the intervention from four possible options (vegetable availability; picky eating; modeling; family meals). These areas were selected based on Social Cognitive Theory which posits that there is reciprocal interaction between an individual and his/her environment. This theory also highlights the importance of selfefficacy, thus this was a target of the intervention as well ${ }^{20}$. Content on each of the four topics was included in all newsletters, but the order and quantity of the content was adjusted based on the parent-identified intervention goal (See Table 1 for the topics covered in each newsletter). Parents received four 4-page newsletters, one per month that included the child's name and tailored feedback based on data from the self-assessment and phone call. A second phone call occurred in the third month; parents were encouraged to describe successes, use problem-solving to over come barriers, and receive support and encouragement. The final two newsletters were sent following this second call. Control group families received four non-health/nutrition related children's books, one per month.

\section{Measures}

\section{Impact Evaluation}

Child BMI: Trained staff measured (in duplicate) height and weight using a Shorr infant/ child/adult stadiometer and a Seca model 770 electronic personal scale, respectively. Child BMI was determined using height and weight measured at baseline and percentiles were determined based on CDC guidelines. ${ }^{21}$

Child Diet: Information on the child's intake of vegetables was collected using the Block Kids FFQ and analyzed by Block Dietary Data Systems. ${ }^{22}$ Parents completed the FFQ within the week following the child's height and weight measurement. 
Home Physical Environment: A component of the Healthy Home Checklist, asked parents to report whether 18 types of vegetables were present or absent in their home in the past seven days; responses were summed to reflect the types of vegetables available. This parentreport measure has been shown to correlate with vegetable availability $(r=.44, P<.001)^{23}$.

Home Social Environment: The Parenting Survey included a measure of self-efficacy for healthy weight parenting ( 13 items, Cronbach's alpha $=0.74$ ), which is thought to impact child vegetable intake. This measure assessed self-efficacy for feeding practices such as preparing a healthy meal for the child and encouraging the child to eat healthy foods before unhealthy ones, and was developed from a previous study by the authors $(\mathrm{n}=318$, Cronbach's alpha $=0.86$, unpublished data).The Healthy Home Checklist also asked parents about the number of days per week they and their family engaged in certain behaviors, for example, eating dinner away from home.

Demographic Characteristics: Demographic factors, including child age, parent age, role in the home, race/ethnicity, income, marital status, and educational attainment, and number of adults living in the home were collected with the baseline Parenting Survey. With the exception of height, weight, and demographic variables, all measures were repeated at follow-up.

\section{Program Evaluation}

Process Outcomes: Using a 1-5 rating scale( 5 being 'excellent' and 1 being 'poor'), the Program Evaluation asked parents to rate the newsletters, phone calls, and Healthy Home Checklist. In addition, in open response format, parents provided feedback on what they liked and disliked.

\section{Data Analysis}

Statistical analyses were performed using SAS (v9.1, SAS Institute Inc, Cary, NC, 2003). Descriptive statistics were conducted for variable distributions and normality (Shapiro-Wilk W, box-plot, and normal probability plot). Due to non-normality, vegetable intake was logtransformed.

Differences at baseline between the intervention and control groups were examined with Kruskal-Wallis tests (categorical variables) and two-sided students t-tests (continuous variables).

The unadjusted differences in change scores for vegetable consumption and home environment characteristics (vegetable availability, days/week parents reported certain behaviors, and self-efficacy) between intervention and control groups were examined using two-sided student's t-tests. Because of the questionable reliability of using change scores, the effect was further evaluated using linear regression with group (intervention/control) and baseline data as predictors. A second set of models was created adjusting for age, as children in the intervention group were older than those in the control group (Table 2). Relationships were considered significant when $\mathrm{P}<0.05$. 


\section{RESULTS}

Demographic characteristics of the sample are shown in Table 2. Participants only differed based on child age $(\mathrm{P}=0.01)$. From the four possible target area options, parents selected only availability and picky eating.

\section{Outcome Evaluation}

The results for vegetable intake and availability, days per week of parent-reported behaviors, and self-efficacy are presented in Table 3. At baseline, there were no significant differences. Non-potato vegetable availability significantly differed between groups only when the difference in mean change scores ( 1.55 for the intervention group and -0.33 for the control group) was examined $(\mathrm{t}(41)=-2.39, \mathrm{P}=0.02)$. When the data were assessed using linear regression, group assignment was not a significant predictor of follow-up availability. Intervention parents significantly increased the number of times/week they suggested their child have a fruit or vegetable for a snack by 0.95 and decreased the number of days/week they prepared a special meal for their child by 4.5 days per week compared to the control group -.05 and +.20 days per week, respectively. Self-efficacy improved significantly in the intervention group compared to the control group before $(\mathrm{P}=0.03)$, but not after adjustment $(\mathrm{P}=0.14)$.The difference in change vegetable intake between groups was not statistically significant before $(\mathrm{P}=0.86)$ or after adjustment $(\mathrm{P}=0.61)$.

\section{Process Evaluation}

Ninety percent of parents $(\mathrm{n}=21)$ rated the newsletters four or five, out of five, and $76 \%$ reported the recipes and food preparation suggestions were the most helpful aspects of the newsletters. Phone calls ranged in length from 11-45 minutes (mean=34). Call length and vegetable intake were unrelated at baseline or change in vegetable intake. Fourteen of 21 parents who completed program evaluations rated the phone calls as 'very helpful'. In general, these parents liked the more personalized feel and the opportunity to talk about their goals as well as the professional information. Other parents $(n=4)$, found the calls to be 'time-consuming' and 'not offering much new information'. More than $75 \%$ of intervention parents thought the self-assessments were helpful as a reflective tool and useful in identifying areas for improvement.

\section{DISCUSSION}

Using a mail- and telephone-based intervention to modify children's intake of vegetables, we showed that an intervention requiring minimal resources and easy dissemination could favorably affect physical and social characteristics of the home food environment. This finding is consistent with other studies that have shown improvements to the home environment and dietary behaviors in children and parents ${ }^{10}$. Unlike previous studies that focused on both fruits and vegetables, the current intervention focused only on vegetables, since parents often report getting their children to eat vegetables to be a particular challenge. We hypothesized that selecting a specific behavior would be more manageable, due to the minimal nature of the intervention. 
Previous research has shown positive associations between home food availability and dietary intake in children ${ }^{24}$, and the current study confirmed that vegetable availability correlated with vegetable intake in this population $(\mathrm{r}=0.32, \mathrm{p}=0.04)$. Food selection is partially determined by social learning, experience, and exposure ${ }^{25}$, especially for young children, for whom availability depends upon the environment established by others ${ }^{24}$. This emphasizes the importance of the positive effects of the current intervention on vegetable availability. Evidence from a small number of other intervention studies also showed increases in vegetable availability in intervention compared to control homes ${ }^{10}$. The change in self-efficacy observed in this study may be particularly relevant, as parents of preschoolaged children have identified low self-efficacy as a barrier to serving fruits and vegetables. ${ }^{26,27}$

Process measures demonstrated that parents appreciated and used the vegetable preparation suggestions such preparing vegetables so they are ready for snacks and the child-friendly recipes provided, possibly explaining the increase in the number of times/week intervention group parents suggested fruits and vegetables as snacks. Intervention parents reported that (1) they learned that foods need to be offered many times to their child, if it is rejected initially, (2) children should be involved in meal preparation, and (3) parents need to offer variety and choice to increase vegetable consumption. Wardle et al. showed that changing parental feeding practices when offering vegetables, such as eating the food in front of the child and offering the vegetables multiple times after an initial rejection, can increase children's acceptance of and preference for vegetable ${ }^{11}$.

The study sample was mainly Caucasian with income and education levels higher than the state average, limiting the generalizability of results. Further, the self-selected nature of the study's convenience sample may have resulted in a biased sample of those actively interested in enhancing their child's diet. One of the recruitment methods, use of a university listserv, was larger and faster than expected, possibly explaining the disproportionate inclusion of individuals from higher income and education groups. Even in this population, parents were seeking advice about challenges with their children's diets. Use of a monetary incentive to complete the data collection, even in this motivated population, may have affected parents' survey responses and/or feeding behaviors.

Parent assessment of child diet by FFQ may not have accurately reflected children's diets or may not have been sensitive enough to detect changes in vegetable intake. In addition, 85\% of the children attended child care making reporting of weekday foods difficult. However, parent-reported fruit and vegetable intake using an FFQs has been shown to correlate with plasma carotenoid levels ${ }^{28}$. Home environment data, also collected by parent-report, may have been affected by social desirability bias. The power to detect significant results in this study was limited by sample size; based on group means and standard deviations in this sample, 213 families/group would have been required to have $80 \%$ power to find significant differences in vegetable intake.

Despite these limitations, this study demonstrates that a low-resource and feasible intervention aimed at the parent can lead to changes to the physical and social home food environment. Further studies should include larger, more diverse samples and longer 
intervention and follow-up periods. Additionally, future work should investigate methods to complete more frequent assessments and provide tailored feedback using technology (internet and mobile devices), which might increase the extent to which the intervention can be delivered without increasing delivery costs.

\section{IMPLICATIONS FOR RESEARCH AND PRACTICE}

Consistent with previous research, this study has demonstrated that nutrition educators can target parents as agents of change to create home environments thought to encourage healthy dietary intakes for their children. However, this intervention took place over only a short period of four months; future intervention studies should investigate longer-term efforts to alter the environment, such as food availability, parent self-efficacy for healthy weight parenting, and parent feeding practices, and determine the impact of these changes on child food intake.

\section{Supplementary Material}

Refer to Web version on PubMed Central for supplementary material.

\section{Acknowledgments}

Funding for this research was provided by an unrestricted grant from "Get Kids in Action", a partnership between the Gatorade Corporation and UNC. Special thanks to Dr. Lucia Leone, Dr. May May Leung, and Dr. Michael Bowling for their help with editing this manuscript. This work was part of Rachel Tabak's dissertation.

\section{References}

1. Heidemann C, Schulze MB, Franco OH, van Dam RM, Mantzoros CS, Hu FB. Dietary patterns and risk of mortality from cardiovascular disease, cancer, and all causes in a prospective cohort of women. Circulation. Jul 15; 2008 118(3):230-237. [PubMed: 18574045]

2. Vioque J, Weinbrenner T, Castello A, Asensio L, Garcia de la Hera M. Intake of fruits and vegetables in relation to 10-year weight gain among Spanish adults. Obesity (Silver Spring). Mar; 2008 16(3):664-670. [PubMed: 18239583]

3. Mikkila V, Rasanen L, Raitakari OT, Pietinen P, Viikari J. Consistent dietary patterns identified from childhood to adulthood: the cardiovascular risk in Young Finns Study. Br J Nutr. Jun; 2005 93(6):923-931. [PubMed: 16022763]

4. Mauras N, Delgiorno C, Kollman C, et al. Obesity without Established Comorbidities of the Metabolic Syndrome Is Associated with a Proinflammatory and Prothrombotic State, Even before the Onset of Puberty in Children. J Clin Endocrinol Metab. Jan 8.2010

5. Uauy R, Solomons N. Diet, nutrition, and the life-course approach to cancer prevention. J Nutr. Dec; 2005 135(12 Suppl):2934S-2945S. [PubMed: 16382507]

6. Ness AR, Maynard M, Frankel S, et al. Diet in childhood and adult cardiovascular and all cause mortality: the Boyd Orr cohort. Heart. Jul; 2005 91(7):894-898. [PubMed: 15958357]

7. Usual Intake of Total Vegetables, Excluding Cooked Dry Beans \& Peas. Applied Research Program. National Cancer Institute; 2011. Risk Factor Monitoring and Methods Branch Web site. http://riskfactor.cancer.gov/diet/usualintakes/pop/veg_nopeabean.html [Accessed May 25, 2011]

8. Savage JS, Fisher JO, Birch LL. Parental influence on eating behavior: conception to adolescence. J Law Med Ethics. Spring;2007 35(1):22-34. [PubMed: 17341215]

9. Brug J, Tak NI, te Velde SJ, Bere E, de Bourdeaudhuij I. Taste preferences, liking and other factors related to fruit and vegetable intakes among schoolchildren: results from observational studies. Br J Nutr. Feb; 2008 99(Suppl 1):S7-S14. [PubMed: 18257952] 
10. Haire-Joshu D, Elliott MB, Caito NM, et al. High 5 for Kids: The impact of a home visiting program on fruit and vegetable intake of parents and their preschool children. Prev Med. Apr 9.2008

11. Wardle J, Cooke LJ, Gibson EL, Sapochnik M, Sheiham A, Lawson M. Increasing children's acceptance of vegetables; a randomized trial of parent-led exposure. Appetite. Apr; 2003 40(2): 155-162. [PubMed: 12781165]

12. Gibson EL, Wardle J, Watts CJ. Fruit and vegetable consumption, nutritional knowledge and beliefs in mothers and children. Appetite. Oct; 1998 31(2):205-228. [PubMed: 9792733]

13. Jaramillo SJ, Yang SJ, Hughes SO, Fisher JO, Morales M, Nicklas TA. Interactive computerized fruit and vegetable preference measure for African-American and Hispanic preschoolers. J Nutr Educ Behav. Nov-Dec;2006 38(6):352-359. [PubMed: 17142191]

14. Golan M, Crow S. Targeting parents exclusively in the treatment of childhood obesity: long-term results. Obes Res. Feb; 2004 12(2):357-361. [PubMed: 14981230]

15. Golan M, Kaufman V, Shahar DR. Childhood obesity treatment: targeting parents exclusively v. parents and children. Br J Nutr. May; 2006 95(5):1008-1015. [PubMed: 16611394]

16. Bauman KE, Ennett ST, Foshee VA, Pemberton M, King TS, Koch GG. Influence of a family program on adolescent smoking and drinking prevalence. Prev Sci. Mar; 2002 3(1):35-42. [PubMed: 12002557]

17. Morawska A, Sanders MR. Self-administered behavioral family intervention for parents of toddlers: Part I. Efficacy. J Consult Clin Psychol. Feb; 2006 74(1):10-19. [PubMed: 16551139]

18. Ennett ST, Bauman KE, Pemberton M, et al. Mediation in a family-directed program for prevention of adolescent tobacco and alcohol use. Prev Med. Oct; 2001 33(4):333-346. [PubMed: 11570838]

19. Knai C, Pomerleau J, Lock K, McKee M. Getting children to eat more fruit and vegetables: A systematic review. Prev Med. 2006; 42(2):85-95. [PubMed: 16375956]

20. Gaines A, Turner LW. Improving Fruit and Vegetable Intake Among Children: A Review of Interventions Utilizing the Social Cognitive Theory. California Journal of Health Promotion. 2009; 7(1):52-66.

21. CDC. A SAS Program for the CDC Growth Charts. 2009. http://www.cdc.gov/nccdphp/dnpao/ growthcharts/resources/sas.htm

22. Block Questionnaire for Ages 8-17 - 2004 FFQ. Block Questionnaires. http://nutritionquest.org/ assessment/list-of-questionnaires-and-screeners/

23. Marsh T, Cullen KW, Baranowski T. Validation of a fruit, juice, and vegetable availability questionnaire. J Nutr Educ Behav. Mar-Apr;2003 35(2):93-97. [PubMed: 12725715]

24. Baranowski T, Cullen KW, Baranowski J. Psychosocial correlates of dietary intake: advancing dietary intervention. Annu Rev Nutr. 1999; 19:17-40. [PubMed: 10448515] 


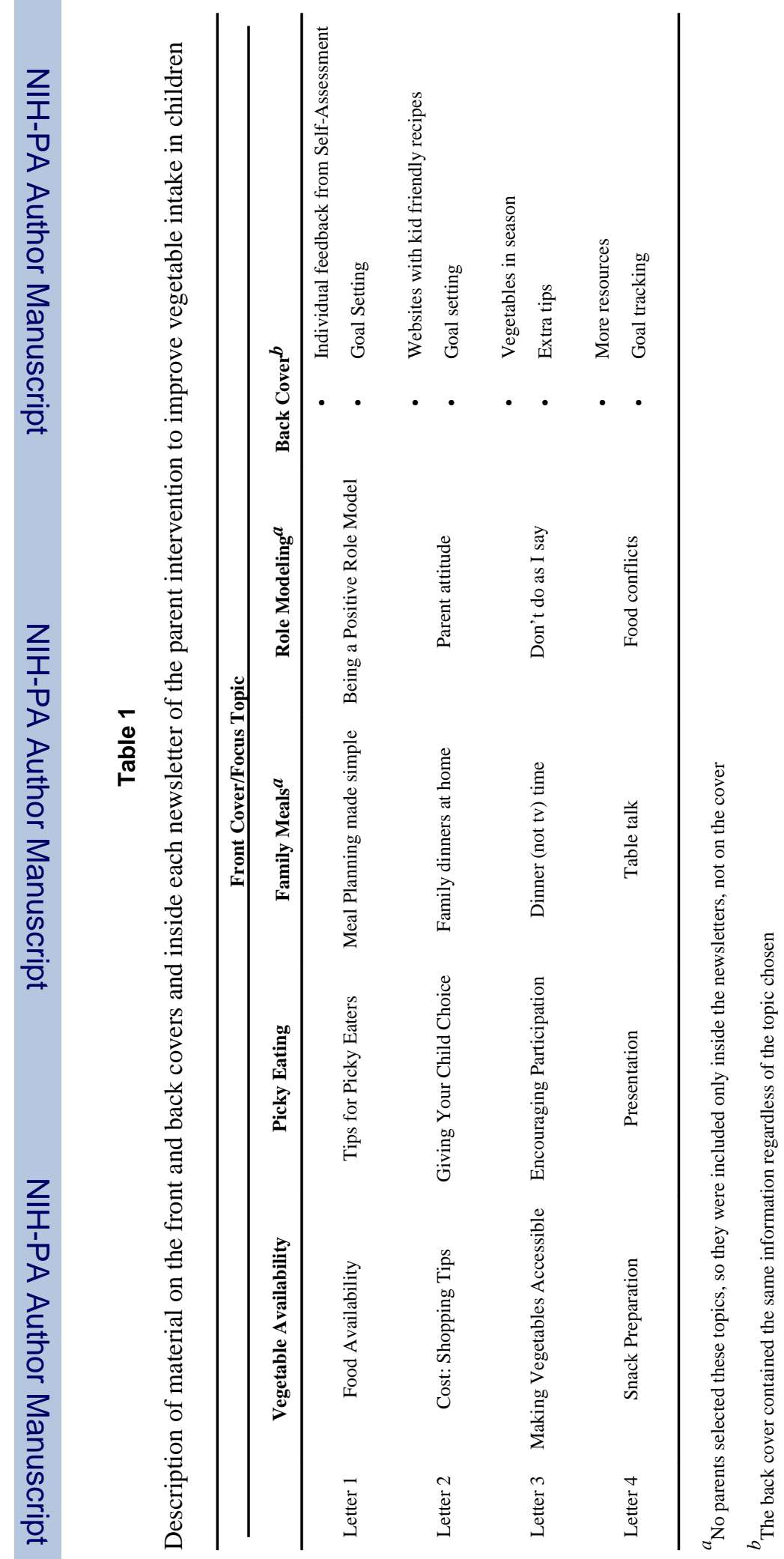


Table 2

Characteristics of the sample included in the Family Ties to Health Study

\begin{tabular}{|c|c|c|c|c|}
\hline & & Total Sample $(n=43)$ & Intervention $(n=22)$ & Control $(n=21)$ \\
\hline Variable & Category & Mean (sd) & Mean (sd) & Mean (sd) \\
\hline Child Age ${ }^{a}$ & Years & $3.6(0.8)$ & $3.9(0.7)$ & $3.3(0.9)$ \\
\hline Parent Age & Years & $36.4(5.4)$ & $36.6(6.1)$ & $36.2(4.7)$ \\
\hline \multirow[t]{2}{*}{ Parent BMI } & & $26.4(5.4)$ & $26.6(5.1)$ & $26.1(5.6)$ \\
\hline & & $\mathrm{n}(\%)$ & $\mathrm{n}(\%)$ & $\mathrm{n}(\%)$ \\
\hline \multirow{2}{*}{ Race/Ethnicity } & White (non-Hispanic) & $37(86.1)$ & $18(81.8)$ & $19(90.5)$ \\
\hline & Non-White & $6(13.9)$ & $4(18.2)$ & $2(9.5)$ \\
\hline \multirow{2}{*}{ Child Weight Status ${ }^{b}$} & $\mathrm{BMI}<85 \%$ & $32(74.4)$ & $17(77.3)$ & $15(71.4)$ \\
\hline & $\mathrm{BMI} \geq 85 \%$ & $11(25.6)$ & $5(22.7)$ & $6(28.6)$ \\
\hline \multirow{4}{*}{ Primary Care Giver BMI } & $<18.5$ & $1(2.4)$ & $1(4.5)$ & 0 \\
\hline & $18.5-24.9$ & $18(43.9)$ & $8(36.4)$ & $10(52.6)$ \\
\hline & $25-29.9$ & $13(31.7)$ & $8(36.4)$ & $5(26.3)$ \\
\hline & 230.0 & $9(21.9)$ & $5(22.7)$ & $4(21.0)$ \\
\hline \multirow{3}{*}{ Income (USD) } & Less than $\$ 50,000$ & $8(18.6)$ & $4(18.2)$ & $4(81.0)$ \\
\hline & $\$ 50,000$ or higher & $34(79.1)$ & $17(77.3)$ & $17(19.0)$ \\
\hline & missing & $1(2.3)$ & $1(4.5)$ & 0 \\
\hline \multirow{2}{*}{ Gender-Child } & Male & $16(37.2)$ & $9(40.9)$ & $7(36.8)$ \\
\hline & Female & $27(62.8)$ & $13(59.1)$ & $14(66.7)$ \\
\hline \multirow{2}{*}{ Gender-Parent } & Male & $5(12)$ & $3(14)$ & $2(10)$ \\
\hline & Female & $36(88)$ & $19(86)$ & $19(90)$ \\
\hline \multirow{3}{*}{ Days/week in Childcare } & 0 & $6(14.6)$ & $3(13.6)$ & $3(15.8)$ \\
\hline & $1-4$ & $10(24.4)$ & $7(31.8)$ & $3(15.8)$ \\
\hline & 25 & $25(61.0)$ & $12(54.5)$ & $13(68.4)$ \\
\hline \multirow{3}{*}{ Hours/day in Childcare } & 0 & $6(14.6)$ & $3(13.6)$ & $3(15.8)$ \\
\hline & $1-7.5$ & $11(26.8)$ & $6(27.3)$ & $5(26.3)$ \\
\hline & 28 & $24(58.5)$ & $13(59.7)$ & $11(57.9)$ \\
\hline \multirow{2}{*}{ Marital Status } & Married/living with partner & $37(86.0)$ & $18(81.8)$ & $19(90.5)$ \\
\hline & Divorced/separated/single & $6(14.0)$ & $4(18.2)$ & $2(9.5)$ \\
\hline \multirow{2}{*}{ Education } & More than College & $26(60.5)$ & $14(63.6)$ & $12(57.1)$ \\
\hline & College or Less & $17(39.5)$ & $8(36.4)$ & $9(42.9)$ \\
\hline
\end{tabular}

J Nutr Educ Behav. Author manuscript; available in PMC 2014 July 15. 


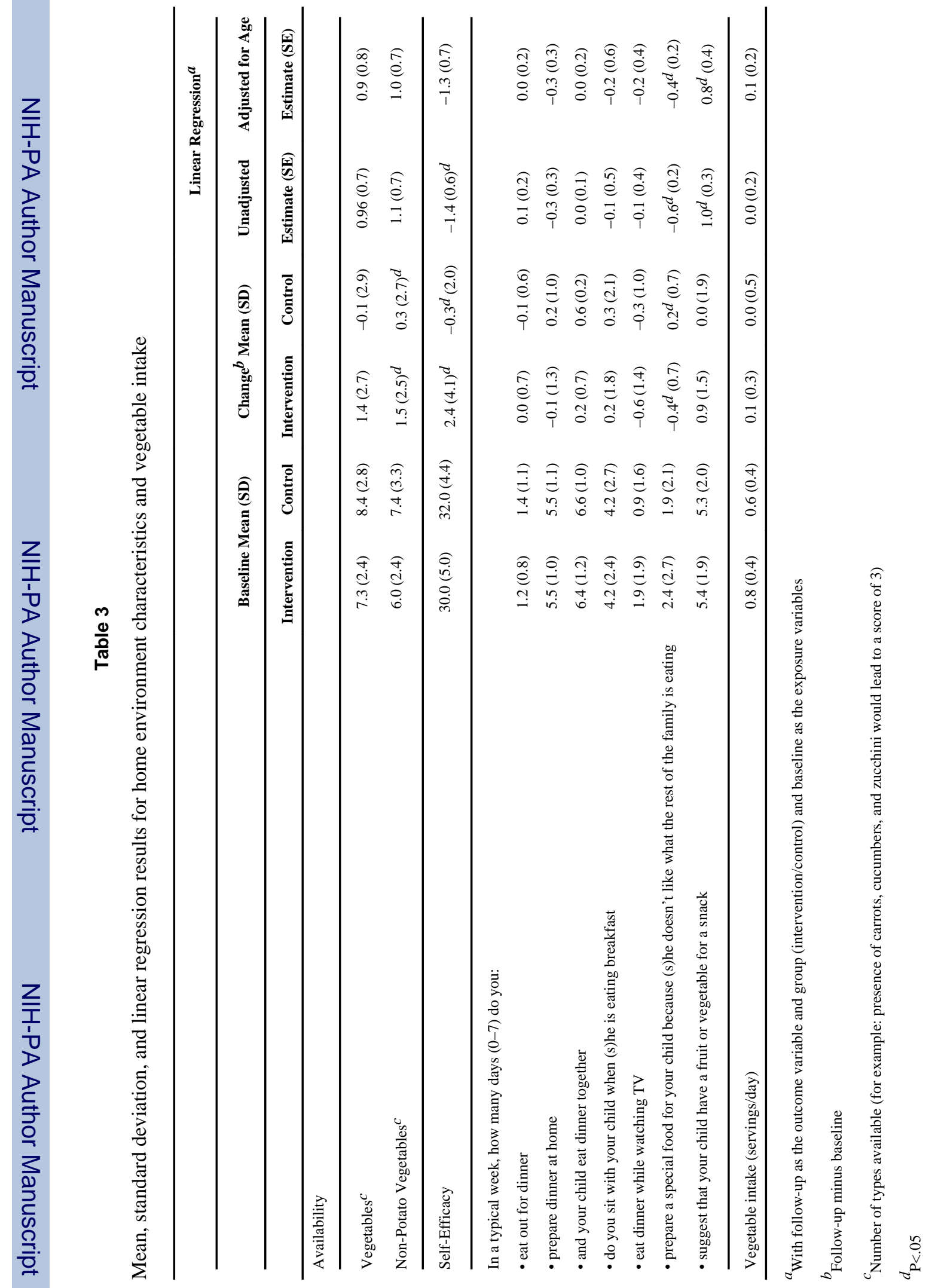

